\title{
102 PHYSICIANS FACED TO TREATMENTS REFUSALS
}

P Biclet ${ }^{1}{ }^{1} / n$ stitut Pasteur Paris

10.1136/bmjspcare-2012-000250.99

French Law allows patients to refuse medical treatments even if they are indispensable for their survival. Faced with this situation, physicians are generally reluctant to stop treatments but finally comply with the patient's will. However they must be certain that the decision is conscious and free. We present different cases: Adult and minor Jehovah witnesses, hunger strikers free or in prisons, patients refusing artificial alimentation, people committing suicide, adolescents refusing cancer chemotherapy and discuss the role of physicians and care team. According the specificities of the different situations, the following points must be checked:

- accurate information about the legal status of the situation faced with,

- confirmation of the patient's decision after a reasonable period,

- information about the nature futile or non futile of the treatment proposed,

- aptitude of the patient to understand physician's proposal and to make up his mind.

- certainty of the patient's age (minor), of the persons titulars of parental authority or identity of the guardians.

Precautions that must be taken by the physician include precise writings of his, diligences, consultation of the care team, recourse to the attorney or to the judge according the country laws. 